University of Nebraska - Lincoln

DigitalCommons@University of Nebraska - Lincoln

\title{
Early spatial and temporal validation of MODIS LAI product in the Southern Africa Kalahari
}

\author{
J. L. Privette \\ NASA's Goddard Space Flight Center \\ R. B. Myneni \\ Boston University \\ Y. Knyazikhin \\ Boston University \\ M. Mukelabai \\ Meteorological Office \\ G. Roberts \\ University College London \\ See next page for additional authors
}

Follow this and additional works at: https://digitalcommons.unl.edu/nasapub

Part of the Physical Sciences and Mathematics Commons

Privette, J. L.; Myneni, R. B.; Knyazikhin, Y.; Mukelabai, M.; Roberts, G.; Tian, Y.; Wang, Y.; and LeBlanc, S. G., "Early spatial and temporal validation of MODIS LAI product in the Southern Africa Kalahari" (2002). NASA Publications. 37.

https://digitalcommons.unl.edu/nasapub/37

This Article is brought to you for free and open access by the National Aeronautics and Space Administration at DigitalCommons@University of Nebraska - Lincoln. It has been accepted for inclusion in NASA Publications by an authorized administrator of DigitalCommons@University of Nebraska - Lincoln. 


\section{Authors}

J. L. Privette, R. B. Myneni, Y. Knyazikhin, M. Mukelabai, G. Roberts, Y. Tian, Y. Wang, and S. G. LeBlanc 


\title{
Early spatial and temporal validation of MODIS LAI product in the Southern Africa Kalahari
}

\author{
J.L. Privette ${ }^{\mathrm{a}, *}$, R.B. Myneni ${ }^{\mathrm{b}}$, Y. Knyazikhin ${ }^{\mathrm{b}}$, M. Mukelabai ${ }^{\mathrm{c}}$, G. Roberts ${ }^{\mathrm{d}}$, Y. Tian ${ }^{\mathrm{b}}$, \\ Y. Wang ${ }^{\mathrm{b}}$, S.G. Leblanc ${ }^{\mathrm{e}}$ \\ ${ }^{a}$ Code 923, NASA's Goddard Space Flight Center, Greenbelt, MD 20771, USA \\ ${ }^{\mathrm{b}}$ Department of Geography, Boston University, 675 Commonwealth Ave., Boston, MA, USA \\ ${ }^{\mathrm{c}}$ Meteorological Office, PO Box 910144, Mongu, Zambia \\ ${ }^{\mathrm{d}}$ Department of Geography, University College London, UK \\ ${ }^{\mathrm{e}}$ Canadian Centre for Remote Sensing, Ottawa, Canada
}

Received 27 March 2001; received in revised form 10 April 2002; accepted 16 April 2002

\begin{abstract}
We evaluate the operational MODIS Leaf Area Index (LAI) product using field-sampled data collected at five sites in southern Africa in March 2000. One site (Mongu, Zambia) was sampled monthly throughout the year. All sites were along the International Geosphere Biosphere Programme's (IGBP) Kalahari Transect, which features progressively lower annual precipitation, and hence, lower vegetation productivity, from north to south. The soils are consistently sandy. At each site, we sampled the vegetation overstory along three 750-m transects using the Tracing Radiation and Architecture in Canopies (TRAC) instrument. The resulting plant area index values were adjusted with ancillary stem area data to estimate LAI. Despite some instrument characterization and production issues in the first year of MODIS operations, our results suggest the first-year MODIS LAI algorithm correctly accommodates structural and phenological variability in semiarid woodlands and savannas, and is accurate to within the uncertainty of the validation approach used here. Limitations of this study and its conclusions are also discussed.

(C) 2002 Published by Elsevier Science Inc.
\end{abstract}

\section{Introduction}

In November 1999, NASA launched Terra, the first of the major Earth Observing System (EOS) platforms. Terra includes five sensors, including MODerate Resolution Imaging Spectroradiometer (MODIS; Kaufman, Herring, Ranson, $\&$ Collatz, 1998). MODIS is a wide field-of-view $(2330 \mathrm{~km})$ sensor that views most locations each day and all locations within 2 days. Although its heritage primarily includes the Advanced Very High Resolution Radiometer, MODIS has many significant improvements. These include 36 spectral bands at resolutions of 250,500 or $1000 \mathrm{~m}$, on-board calibration systems, and well-characterized performance (e.g., modulation transfer function for precise geolocation).

Despite its technological improvements, Terra may be most noteworthy for ushering in the age of multidisciplinary

\footnotetext{
* Corresponding author. Tel.: +1-301-614-6630; fax: +1-301-614-6695.

E-mail address: jeff.privette@gsfc.nasa.gov (J.L. Privette).
}

operational products. Since 1990, MODIS science teams, stratified by land, atmosphere and ocean disciplines, have been formulating and testing computer algorithms capable of generating global change research parameters in near real-time. A separate team was charged with developing calibration and low-level operational products (e.g., geolocation), and a fifth team was added in 1997 to assist in product validation (Justice, Starr, Wickland, Privette, \& Suttles, 1998; Privette et al., 2000).

The MODIS Land Discipline Team (MODLAND) has a particularly challenging role in generating a wide variety of global products at vastly different temporal and spatial scales (Justice et al., 1998). Perhaps one of the mostly widely anticipated MODLAND products is leaf area index (LAI), a unitless parameter describing the mean green leaf area per given land area (Myneni et al., 2002, this issue). The popularity of LAI stems from its use in many applications, such as modeling atmospheric carbon assimilation, evapotranspiration, fire fuel potential, habitat characteristics and herbivore grazing potential. Further, the MODIS prod- 
uct is the only operational LAI product from satellites currently available.

The importance of LAI led to its emphasis within Southern Africa Validation of EOS (SAVE; Privette, 2000), a validation project funded by the EOS Validation Program Office. SAVE was designed to validate land and atmospheric products from several EOS sensors at multiple field sites. It also served as one of the foundational projects for the Southern African Regional Science Initiative (SAFARI 2000; Swap \& Annegarn, 1999). The fieldwork reported here was conducted under the auspices of this international initiative.

This article describes the methods and early results of SAVE's LAI validation activities in Zambia and Botswana. Following a brief description of the MODIS LAI product, we outline our field sites and sampling methods. Next, we quantitatively evaluate the MODIS LAI against the field measurements in both time and space. We conclude with a discussion of possible errors in both the satellite and field measurements.

This article focuses on data collected in the year 2000 and processed with the so-called MODAPS V001 system. We note that MODIS "first light" was 24 February 2000, the LAI product release occurred in early August, and updates to "lower level" products (such as calibration, cloud masking, and atmospheric correction) occurred throughout 2000 as understanding of sensor and algorithm characteristics grew. These changes led to variable accuracy in some higher-level products. We provide this early assessment of LAI to help benchmark and allow tracking of product accuracy, especially following sensor or algorithm changes, throughout the mission. Further, we hope to provide some transparency to the EOS end-user community on one activity being used to ascribe operational product accuracy. Finally, these results may help guide other operational product teams (e.g., from EOS Aqua, National Polar Orbiting Operational Environmental Satellite System [NPOESS], Global Land Imager) developing their algorithmic approaches.

\section{The MODIS LAI product}

The MODIS LAI product (MOD 15A2; Level 4) is defined as the one-sided green leaf area per unit area. The $1-\mathrm{km}$ product is produced on a daily or 8-day compositing period, where the selected value in a compositing period is that with the highest corresponding fraction of absorbed photosynthetically active radiation (FPAR). We provide a brief summary below, and refer readers elsewhere (Myneni et al., 2002, this issue) for further details.

The algorithm is based on rigorous three-dimensional radiative transfer theory (Myneni, Asrar, \& Gerstl, 1990), but is optimized for inversion using look-up tables and sophisticated approaches to solving the radiative transport equation (Knyazikhin, Martonchik, Myneni, et al., 1998; Knyazikhin, Martonchik, Diner, et al., 1998). The algorithm ingests atmospherically corrected bidirectional reflectance factors, and their corresponding sun-view geometries, in up to seven spectral bands $(648,858,470,555,1240$ and 2130 $\mathrm{nm})$. To date, only two bands (648 and $858 \mathrm{~nm}$ ) are being used. The $250 \mathrm{and} /$ or $500 \mathrm{~m}$ resolution bands are aggregated into normalized $1 \mathrm{~km}$ resolution grid cells prior to ingest (Wolfe, Roy, \& Vermote, 1998).

The algorithm also employs a $1 \mathrm{~km}$ landcover map stratified by six major world biomes. The biomes are used to define unique model configurations, including some fixed parameter values, appropriate for the biome characteristics. Look-up tables are then generated for each biome by running the model for various combinations of LAI and fractional cover. During algorithm execution, the algorithm compares the modeled and observed reflectances for a suite of canopy structures and soil patterns that represent the range of expected natural conditions. All canopy/soil patterns for which modeled and observed reflectances differ by less than the uncertainty of the observed reflectances are considered acceptable solutions. A scale-independent test of energy conservation is also applied. The mean LAI and FPAR for this solution set are reported as the MODIS LAI and FPAR product values. When acceptable solutions are not found, a backup algorithm based on directional vegetation indices is employed.

The LAI product is reprojected onto an Integerized Sinusoidal (IS) $10^{\circ}$ grid. It is distributed in HDF-EOS format and includes extensive quality control and assurance information. In this study, we used the daily $1 \mathrm{~km}$ product values closest to the field-measurement dates when MODIS quality control fields indicated good quality. In the absence of good quality retrievals (e.g., due to persistent cloudiness, data loss or instrument problems), the 8-day composite product was used if its quality control fields indicated good quality.

\section{Field sites}

The field sites used in this study occur along a $\sim 950 \mathrm{~km}$ north-south transect extending from Mongu, Zambia to Tshane, Botswana (see Fig. 1). This transect is a subsection of the Kalahari Transect (Scholes \& Parsons, 1997, Ringrose \& Chanda, 2000), one of the International Geosphere Biosphere Programme's (IGBP) Terrestrial Transects (Steffen, 2000). The Transects span significant variations in major environmental or land-use factors. The Kalahari Transect extends over a rainfall gradient $(\sim 200$ to $\sim 1000 \mathrm{~mm} /$ year) in an area of fairly constant soil types: the Kalahari sands. There is some local soil variation associated with pans and subsurface duricrusts. All sites are on the southern African plateau with elevations of about $1000 \mathrm{~m}$.

Two types of LAI assessments are discussed in this study. First, five sites were characterized over a 20-day period in March 2000 (Dowty et al., 2000). Second, one of those sites (Mongu) was resampled approximately monthly from April through December. Below, we briefly summarize key features of each site. 


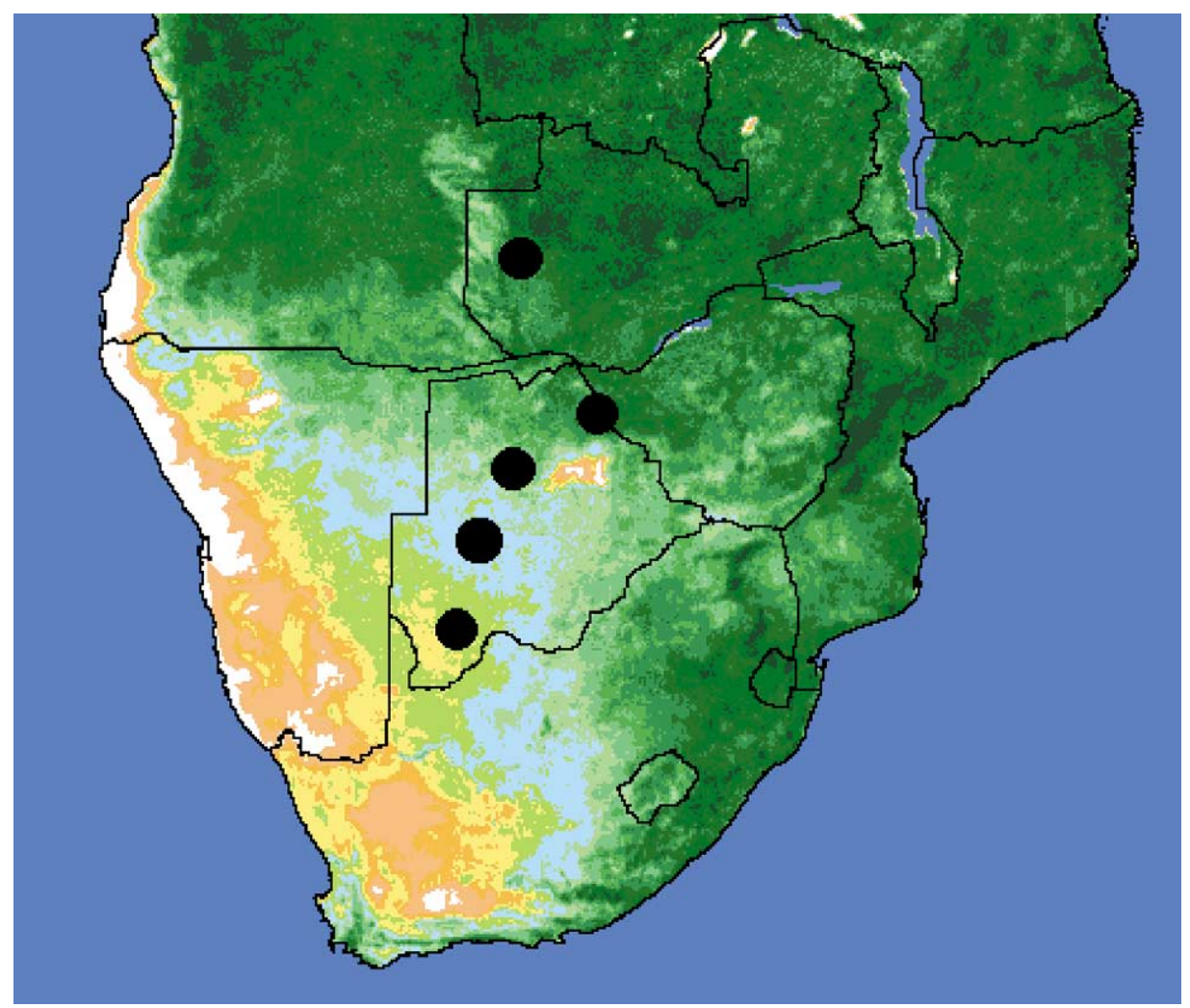

Fig. 1. Map of southern Africa showing measurement sites used in this study. From north to south, the sites are Mongu, Zambia, and Pandamatenga, Maun, Okwa River Crossing and Tshane, Botswana. The image qualitatively corresponds to the mean composited NDVI for first 10 days of years $1982-1993$, where yellow represents more desert-like conditions, and green represents more dense vegetation.

\subsection{Mongu, Zambia-15.438 south; 23.253 east}

This site is on the edge of the Kataba Local Forest, approximately $20 \mathrm{~km}$ south of Mongu, Zambia. The vegetation cover is Kalahari woodland (also known as Miombo woodland on sand) dominated by Brachystegia spiciformis (a broadleaf semi-evergreen with alternate pinnate leaves), with a sparse woody understory (see Fig. 2a; Storrs, 1995). The Local Forest designation implies that the area can be used for government-regulated subsistence harvesting (usually for firewood or lumber) by local villagers. As one of the EOS Land Validation Core Sites, the site features a climb-up $30 \mathrm{~m}$ tower amidst the $\sim 12 \mathrm{~m}$ trees. The mean annual rainfall is about $950 \mathrm{~mm}$.

\subsection{Pandamatenga, Botswana-18.655 south; 25.500 east}

This site is approximately $100 \mathrm{~km}$ south of Kasane, Botswana. The vegetation cover is an open woodland dominated by Schinzophyton rautanenii (a broadleaf deciduous with heavy, spreading crowns and palmate leaves), Baikiaea plurijuga (common name Zambezi teak, a broadleaf with dense crowns and pinnately compound leavesdeciduous to nearly evergreen) and Burkea africana (a deciduous or semi-deciduous broadleaf with bipinnately compound leaves at branch ends) with patches of high grass biomass (see Fig. 2b). The overstory height is about $12 \mathrm{~m}$. The site is subjected to light sheep grazing. The mean annual rainfall is about $630 \mathrm{~mm}$.

\subsection{Maun, Botswana-19.923 south; 23.594 east}

This site is about $20 \mathrm{~km}$ northeast of Maun in a woodland managed by the Harry Oppenheimer Okavango Research Centre. The vegetation cover is mopane woodland (Coloophospermum mopane; a broadleaf deciduous with paired leaflets) with some thick patches of Terminalia sericea (a broadleaf deciduous with simple leaves spirally arranged at branch ends) thicket (see Fig. 2c). The mean height of overstory species is about $7 \mathrm{~m}$. There are some adjacent shrubland patches with no overstory members. Mean annual rainfall is about $460 \mathrm{~mm}$.

\subsection{Okwa River Crossing, Botswana-22.409 south; 21.713 east}

This site is located where the Trans-Kalahari Highway crosses the fossil Okwa River bed (dry), approximately 80 $\mathrm{km}$ south of Ghanzi, Botswana. This site has some topographic variation and soil characteristics which distinguish it from the surrounding landscape. The vegetation cover is an open shrubland, dominated by Acacia mellifera, $T$. sericea 
(a)

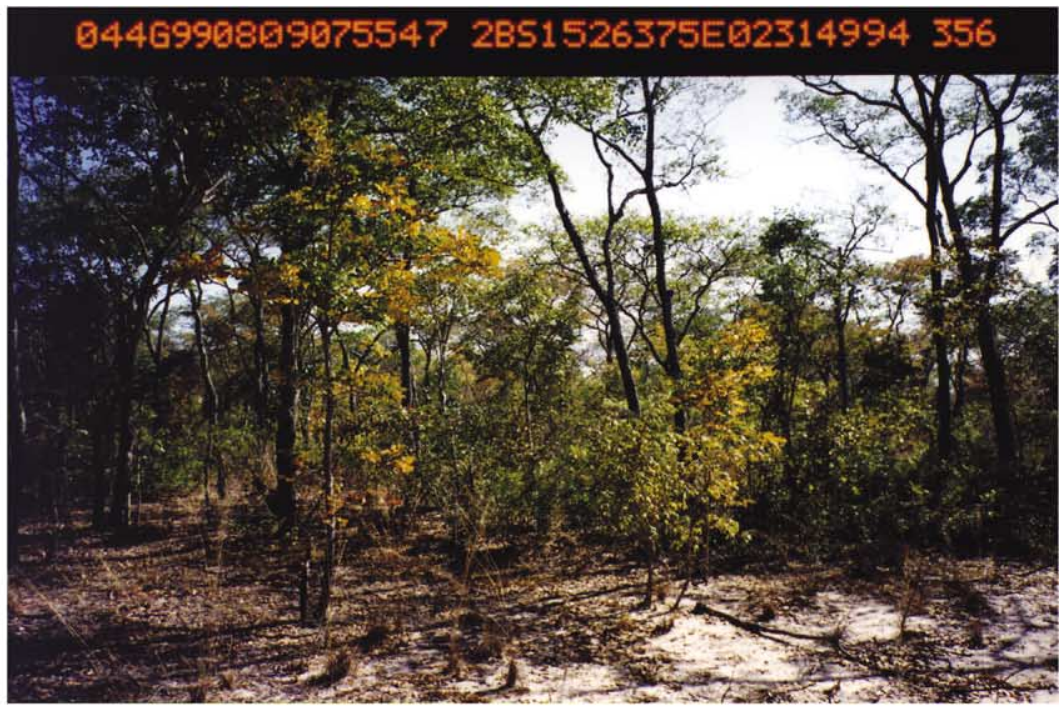

(b)

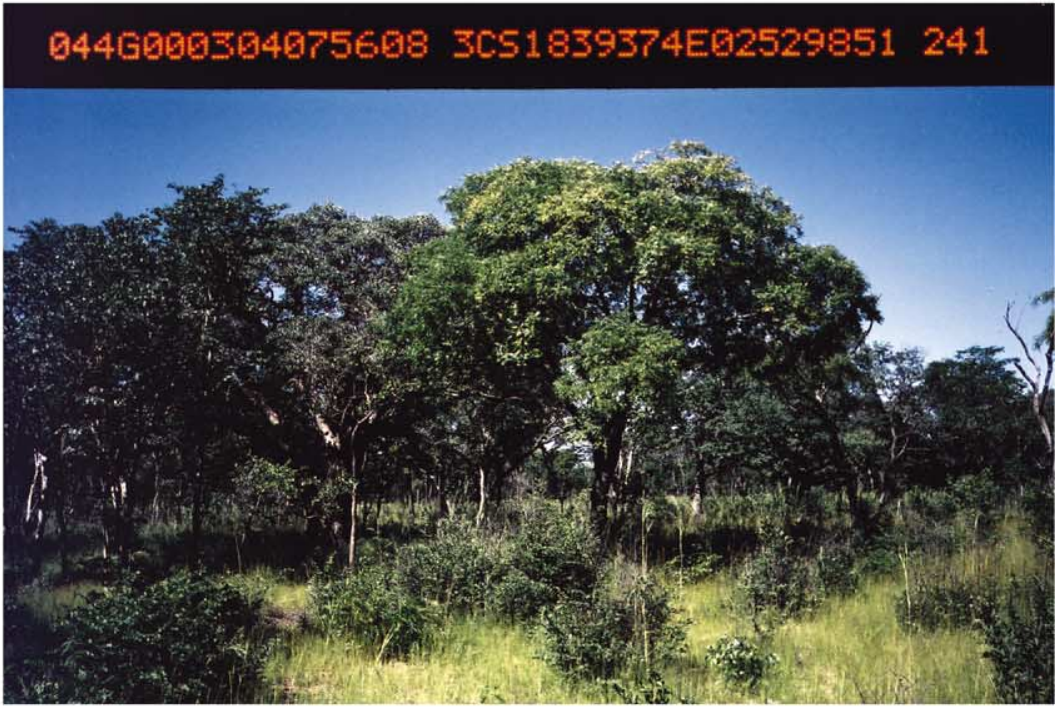

(c)

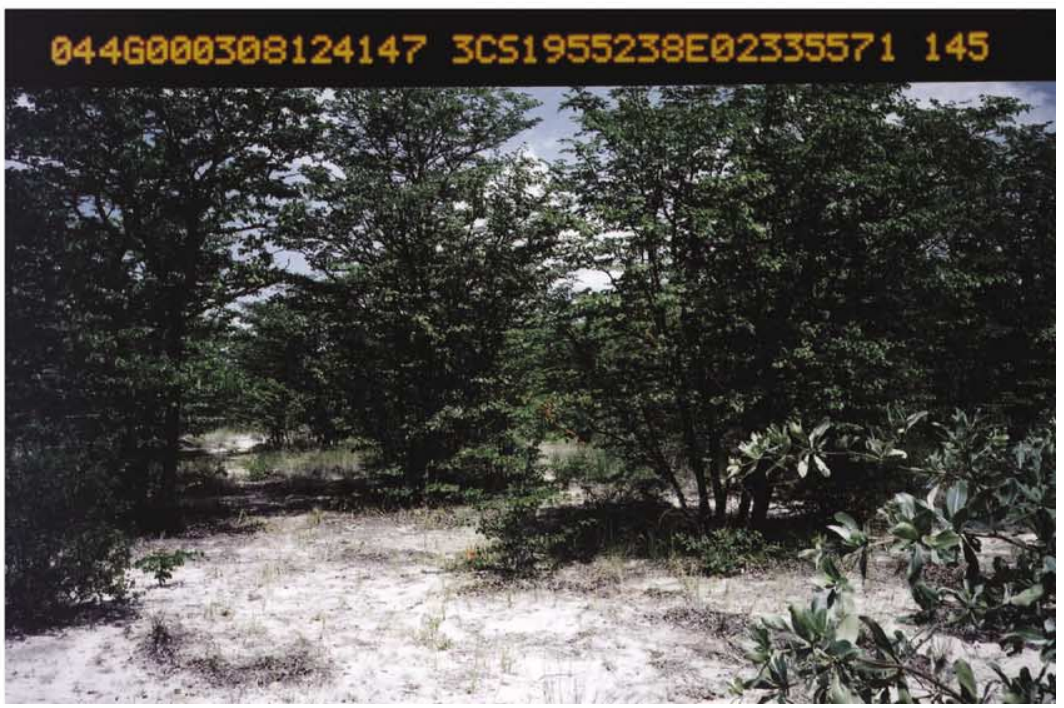

Fig. 2. Photographs of (a) Mongu (August, dry season), (b) Pandamatenga (wet), (c) Maun (wet), (d) Okwa River Crossing (wet), and (e) Tshane (wet). Note the differences in understory, bare soil exposure and canopy density. The numbers, showing the date, Universal Time, and geographic location of the photograph, were determined from the Global Positioning System (GPS). 
(d)

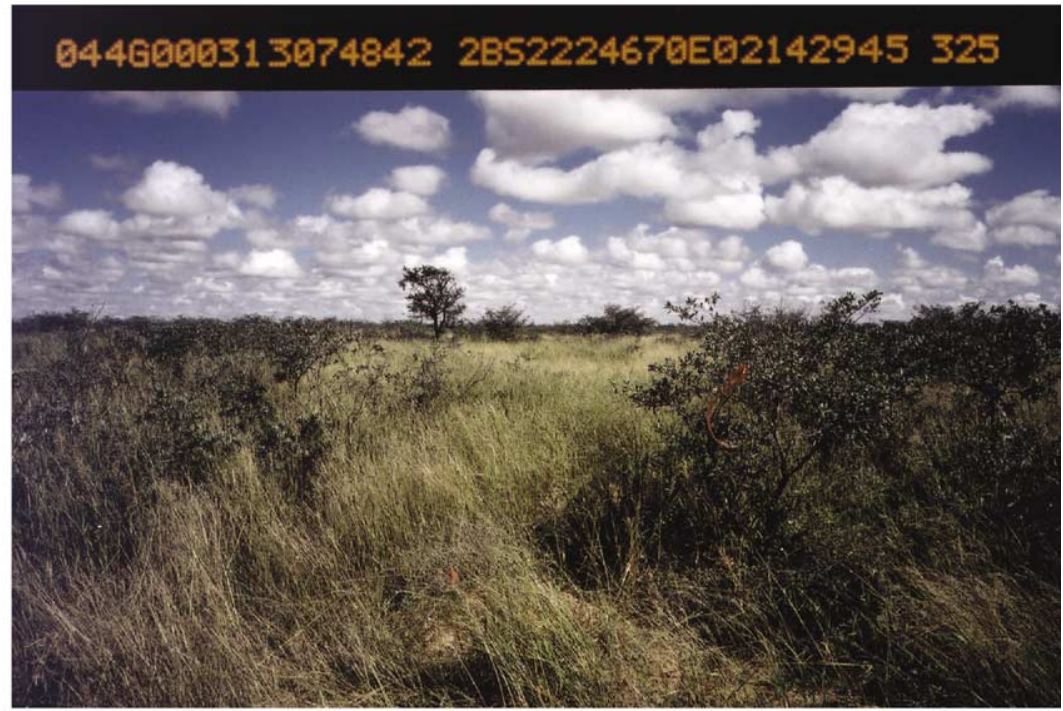

(e)

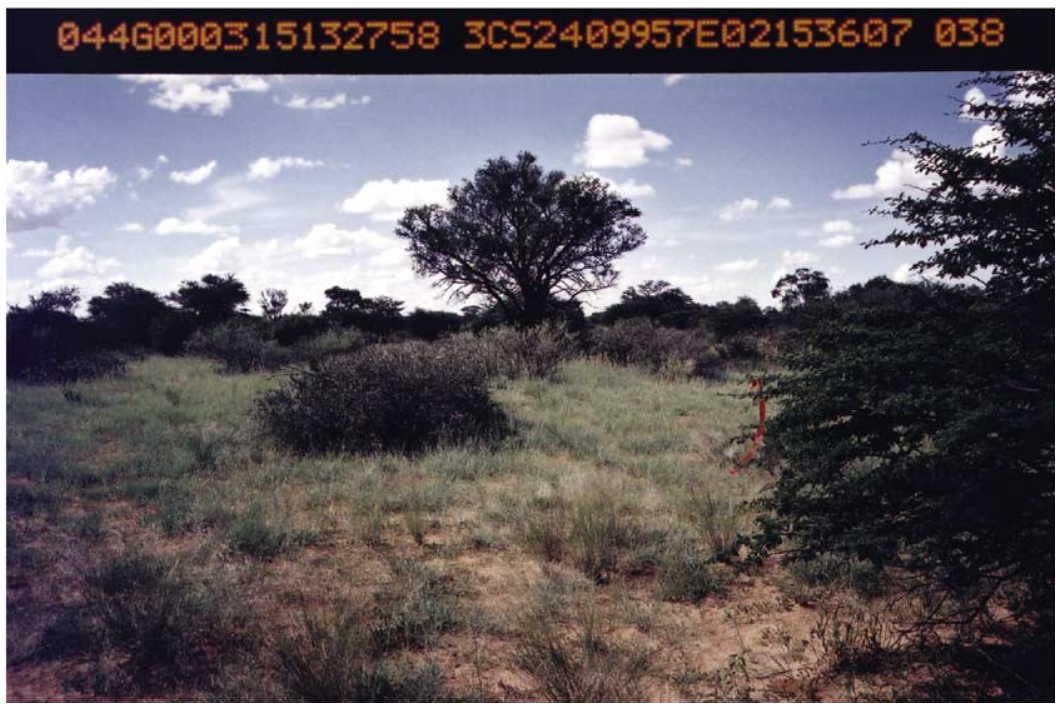

Fig. 2 (continued).

and Grewia flava, with scattered short trees (see Fig. 2d). Mean annual rainfall is about $400 \mathrm{~mm}$.

\subsection{Tshane, Botswana-24.164 south; 21.893 east}

This site is located approximately $15 \mathrm{~km}$ south of Tshane, Botswana. The vegetation cover is open savanna dominated by Acacia luederitzii and A. mellifera with an overstory height of about $7 \mathrm{~m}$ (see Fig. 2e). Mean annual rainfall at Tshane is about $365 \mathrm{~mm}$. Light grazing occurs.

\section{Methods}

\subsection{Instrumentation}

The data used in this study were collected using the Tracing Radiation and Architecture of Canopies (TRAC) instrument developed by Jing Chen and his colleagues (Chen, 1996; Chen \& Cihlar, 1995; Chen, Leblanc, \& Kwong, 2000). TRAC includes three pyranometers (two uplooking, one downlooking) sensitive to photosynthetically active radiation $(400-700 \mathrm{~nm})$. The instrument is hand-carried along linear transects during periods of direct sunlight (i.e., non-cloudy conditions). It effectively samples sunfleck size and frequency by recording the photosynthetic photon flux density (PPFD) at $32 \mathrm{~Hz}$. Each value is recorded as a four-digit integer. The user is required to enter a date/ time stamp in the data (accomplished with the press of a button) at fixed intervals along the transects.

Proprietary TRAC software is used to determine the gap fraction and clumping index of the overstory from one of the uplooking pyranometers (Chen et al., 2000; Leblanc, in press). Clumping is estimated by determining the deviation of the measured gap size distribution from that of randomly distributed foliage (Nilson, 1971; Miller \& Norman, 1971). 
This value is used to adjust the effective plant area index (PAI), which assumes non-clumped foliage, to the actual PAI (Chen, 1996). The PAI is the sum of the LAI and the stem area index (SAI, also referred to as non-photosynthesizing area index), i.e.,

$\mathrm{PAI}=\mathrm{LAI}+\mathrm{SAI}$.

The software requires specification of the canopy characteristic foliage size. We used a value of $40 \mathrm{~mm}$ which is reasonable based on observation, literature (e.g., Storrs, 1995), and limited sampling (G. Midgely, personal communication, 2001). Using TRAC data from June 11 (Mongu, Transect B), we also determined that the derived LAI changed by less than $2 \%$ when specified foliage size was perturbed by $\pm 10 \mathrm{~mm}$. The TRAC solar geometry is computed internally based on the user-provided earth coordinates and the TRAC-recorded date and time.

TRAC was prototyped and has been extensively used in coniferous forests, including use in validation of satellitederived LAI maps of Canada (Chen et al., in press). Its application in woodlands and savannas has been limited to date. Still, the ability of TRAC to compensate for extreme foliage clumping and gaps (and hence deviation from uniform leaf distribution) suggests that it may be one of the more suitable instruments for semiarid systems.

\subsection{Transect design}

We employed the same sampling design at each site. Specifically, we defined three parallel transects, each $750 \mathrm{~m}$ in length and $250 \mathrm{~m}$ apart (Fig. 3). The transects extended in the east-west direction, and were denoted N(orth), A and B from north to south (at Mongu, we denoted these A, B and C). Stake flags were placed each $25 \mathrm{~m}$ to notify the user when to enter a time stamp in the TRAC data record. Distances were determined using an ultrasonic transponder and sensor (Distance Measuring Equipment 201, Haglof Sweden, accurate to $1 \%$ ) and directions determined with a standard compass. This design allowed TRAC to sample an area approximately commensurate with the $1 \mathrm{~km}$ resolution of the MODIS LAI product.

\subsection{Data reduction}

Although TRAC is conceptually easy to operate, field sampling can be challenging especially under variable cloud conditions. Among other duties, the operator must stop motion and deactivate the sensor whenever a cloud passes in front of the sun. Such conditions are frequent in the African rainy season, considering that a single $750 \mathrm{~m}$ transect can take nearly $40 \mathrm{~min}$ to traverse (Chen et al., 2000 recommend a velocity of $0.3 \mathrm{~m} / \mathrm{s}$ ).

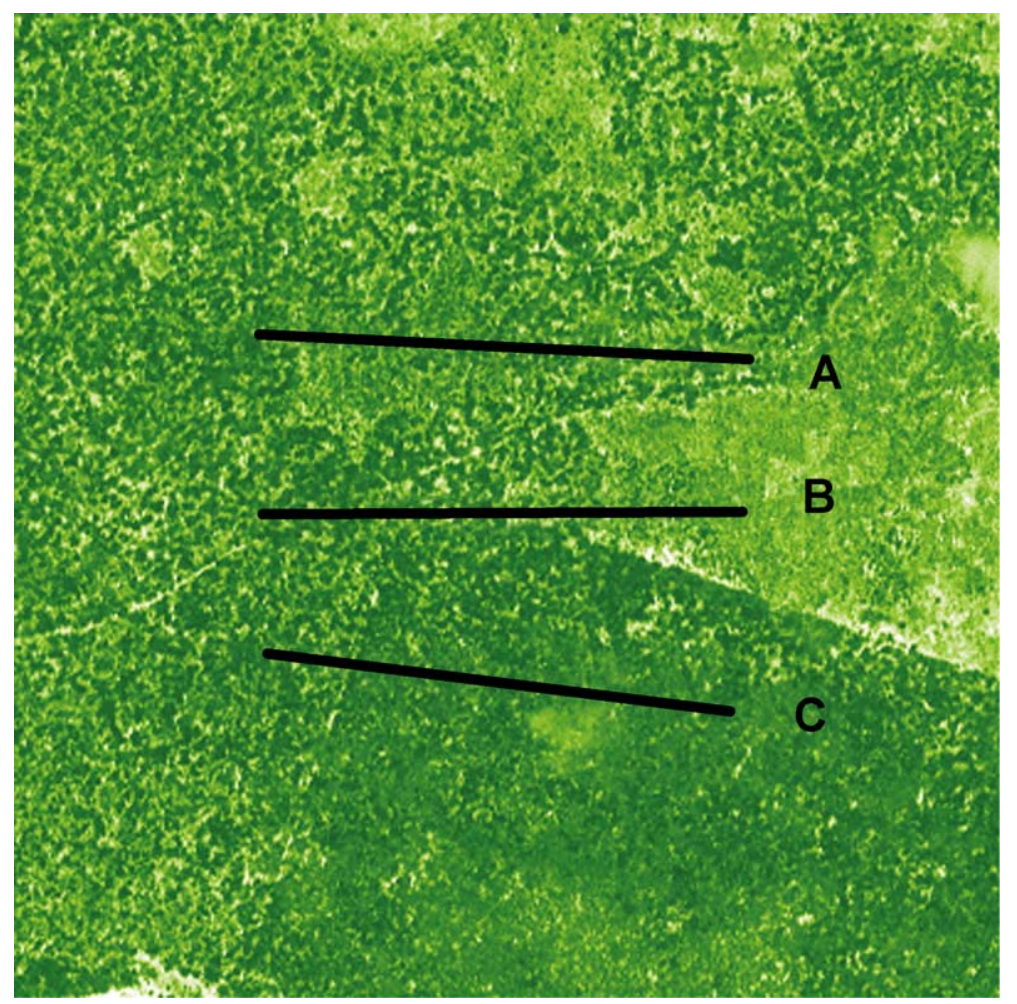

Fig. 3. TRAC sampling occurred along three east-west transects, each $750 \mathrm{~m}$ long and $250 \mathrm{~m}$ apart. Flag stakes were placed each $25 \mathrm{~m}$ to identify TRAC time stamp locations. In this IKONOS NDVI image, darker green patches are typically tree crowns and whiter areas are exposed soil. The darker area emanating from the lower right of the scene is the Kataba Local Forest near Mongu, Zambia. 


\section{PPFD Profile Along Transect}

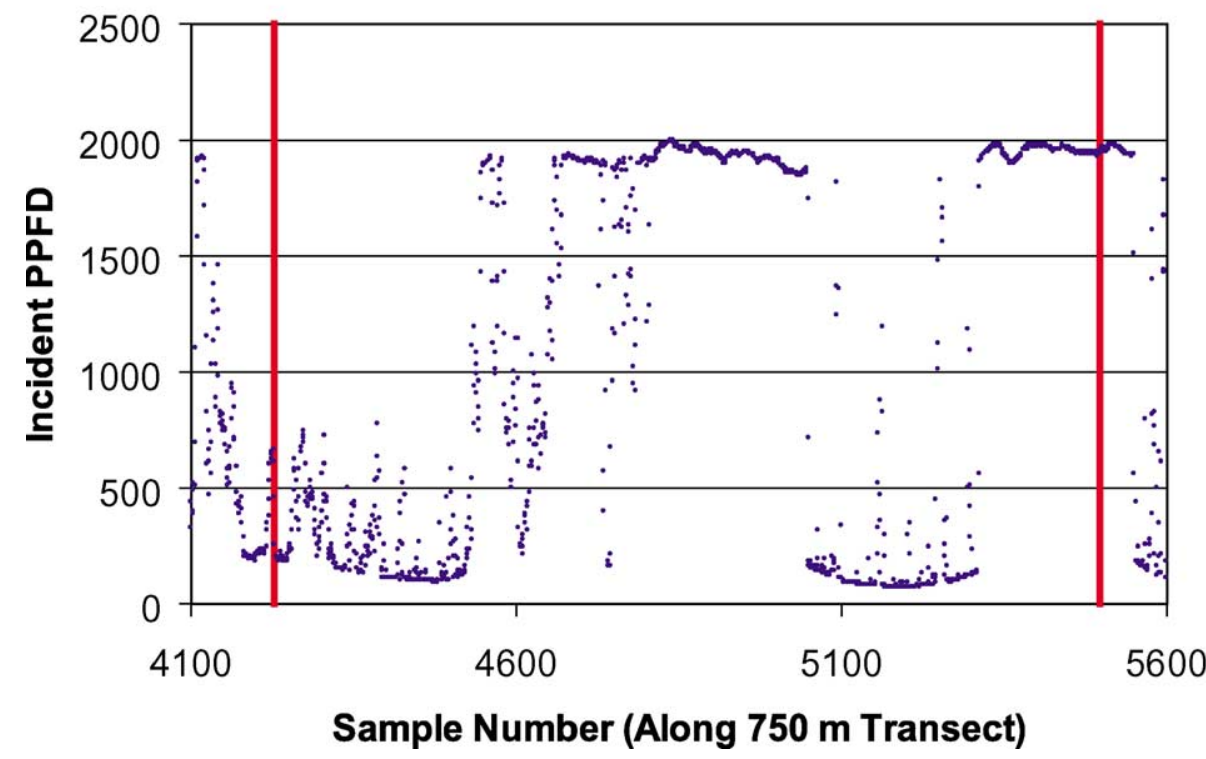

Fig. 4. A subset of PPFD variability along a transect in Kataba Local Forest. The vertical bars indicate stake flag positions demarcating a $25 \mathrm{~m}$ segment. In this example, the segment was traversed in $39 \mathrm{~s}$, resulting in about 1250 samples. The high PPFD values indicate sunflecks caused by within and between crown gaps. The low values indicate shading from overstory components. Note the rounded shape created by samples $5050-5300$ as the TRAC traversed a crown shadow, where the leaf area index was lowest near the edges (more transmittance) and highest near the center (less transmittance).

Occasional anomalies are typically introduced into the data stream through operator error. These may include the absence of a time mark (e.g., if the operator did not see a flag or forgot to press the button), errant time marks (e.g., caused by a tree limb striking the instrument button), or compensating for sensor deactivation/reactivation when a cloud temporarily obscures the sun. Because the data collected on a single transect are voluminous (mean file size is about $700 \mathrm{~Kb}$ ), we developed software, written in Interactive Display Language (IDL), to assist in the visual and statistical detection and correction of anomalies. After data reduction, a typical transect profile contains subsegments of similar PPFD values indicating either crown or gap. Close inspection of these data reveals that TRAC is able to trace the decreasing transmittance from the edge to the center of individual crowns (Fig. 4).

\section{Results}

\subsection{Temporal experiment}

We collected data at Mongu on 12 dates (13 for Transect B) as shown in Table 1. Two tests were initially conducted to assess data validity and suitability. First, to test data consistency over different dates, we computed the mean PPFD value for each of the 30 segments along each transect and for each date. We then correlated the profile of segment means along a transect on each date with those for an arbitrarily chosen date: 2 September. This test reveals whether TRAC captured the same trends in crown density along the transects through the year. Due to tree phenology and solar geometry variability across dates, perfect correlation was not expected.

A sample result for several dates is shown in Fig. 5 and summary results are given in Table 1 . We found that the Pearson coefficient of correlation $(r)$ between different dates generally exceeded 0.65 along Transects A and B, except in cases where the solar zenith angle was greater than about $55^{\circ}$. Further tests suggested that derived LAI values were suspect when data were collected at slightly higher solar zenith angles $\left(\mathrm{SZA}>65^{\circ}\right)$. We also found that correlation results were poorest on Transect $\mathrm{C}$. This result is understandable since that transect is mostly located within the Kataba Local Forest, where crown density varied less relative to the other transects.

A second test was performed by evaluating segment traverse times. Since the canopy clumping factor is determined by the gap size distribution, it is indirectly a function of the TRAC sampling interval. This interval is determined by the speed at which the TRAC is moved. To accurately compare results from different times and places (both along a transect and among different transects), we should have fairly consistent speeds and the sampling interval should be less than the characteristic sunfleck size (a function of foliage gap size and solar geometry). Thus, although there is no "lower limit" on the transit speed, there is an upper limit effectively determined by overstory structure.

We computed the histogram of the 1050 segment transit times available for Mongu (see Fig. 6). The mean traverse time is $47.2 \mathrm{~s}$, with a standard deviation of $8.1 \mathrm{~s}$. For $25 \mathrm{~m}$ 
Table 1

Characteristics of data sets (Transects A to C from top to bottom) collected at Mongu

\begin{tabular}{|c|c|c|c|c|c|c|c|c|}
\hline \multirow[t]{2}{*}{ Filename } & \multirow[t]{2}{*}{ Month } & \multirow[t]{2}{*}{ Day } & \multirow[t]{2}{*}{ PAI } & \multirow[t]{2}{*}{ SZA } & \multicolumn{3}{|l|}{ PPFD } & \multirow[t]{2}{*}{ Correlation } \\
\hline & & & & & Mean & $\mathrm{SD}$ & Maximum & \\
\hline \multicolumn{9}{|l|}{ Transect $A$} \\
\hline MT19040A & 4 & 19 & 2.1 & 26.0 & 1092 & 692 & 2340 & 0.78 \\
\hline MT17050A & 5 & 17 & 1.4 & 44.8 & 776 & 575 & 1591 & 0.79 \\
\hline MT14060A & 6 & 14 & 1.3 & 44.2 & 831 & 557 & 1692 & 0.77 \\
\hline MT29060A & 6 & 29 & 1.2 & 41.4 & 967 & 634 & 1793 & 0.70 \\
\hline MT05080A & 8 & 5 & 1.1 & 42.3 & 954 & 511 & 1612 & 0.91 \\
\hline MT16080A & 8 & 16 & 1.1 & 29.6 & 1196 & 599 & 1860 & 0.92 \\
\hline MT02090A & 9 & 2 & 1.0 & 30.1 & 1073 & 372 & 1512 & 1.00 \\
\hline MT27090A & 9 & 27 & 1.0 & 57.7 & 682 & 287 & 1206 & 0.44 \\
\hline MT17100A & 10 & 17 & 0.9 & 71.3 & 134 & 48 & 307 & 0.52 \\
\hline MT06110A & 11 & 6 & 1.2 & 25.5 & 1304 & 734 & 2083 & 0.61 \\
\hline MT21110A & 11 & 21 & 1.4 & 9.5 & 1334 & 798 & 2229 & 0.63 \\
\hline MT19120A & 12 & 19 & 1.6 & 69.5 & 323 & 215 & 1013 & 0.31 \\
\hline \multicolumn{9}{|l|}{ Transect B } \\
\hline MT29020B & 2 & 29 & 2.1 & 65.3 & 360 & 195 & 1245 & 0.53 \\
\hline MT20040B & 4 & 20 & 1.7 & 36.0 & 817 & 611 & 1863 & 0.87 \\
\hline MT14060B & 6 & 14 & 1.4 & 39.9 & 887 & 601 & 1771 & 0.80 \\
\hline MT29060B & 6 & 29 & 1.4 & 47.9 & 724 & 531 & 1551 & 0.79 \\
\hline MT17070B & 7 & 17 & 1.2 & 37.2 & 938 & 575 & 1697 & 0.83 \\
\hline MT05080B & 8 & 5 & 1.2 & 34.3 & 1057 & 565 & 1825 & 0.90 \\
\hline MT16080B & 8 & 16 & 1.2 & 37.8 & 944 & 542 & 1677 & 0.84 \\
\hline MT02090B & 9 & 2 & 0.9 & 23.8 & 1135 & 373 & 1604 & 1.00 \\
\hline MT27090B & 9 & 27 & 1.1 & 46.5 & 931 & 365 & 1611 & 0.62 \\
\hline MT18100B & 10 & 18 & 1.0 & 41.0 & 1017 & 431 & 1600 & 0.64 \\
\hline MT06110B & 11 & 6 & 1.1 & 15.5 & 1458 & 761 & 2183 & 0.79 \\
\hline MT21110B & 11 & 21 & 1.4 & 6.3 & 1425 & 792 & 2246 & 0.80 \\
\hline MT19120B & 12 & 19 & 1.2 & 69.6 & 326 & 211 & 1013 & -0.15 \\
\hline \multicolumn{9}{|l|}{ Transect $C$} \\
\hline MT20040C & 4 & 20 & 2.4 & 51.5 & 479 & 400 & 1527 & -0.08 \\
\hline MT17050C & 5 & 17 & 2.9 & 35.7 & 746 & 619 & 2041 & 0.27 \\
\hline MT14060C & 6 & 14 & 1.8 & 38.8 & 677 & 574 & 1708 & 0.40 \\
\hline MT07070C & 7 & 7 & 1.8 & 41.5 & 701 & 593 & 1773 & 0.43 \\
\hline MT17070C & 7 & 17 & 1.6 & 45.8 & 637 & 492 & 1605 & 0.37 \\
\hline MT07080C & 8 & 7 & 1.3 & 34.0 & 936 & 558 & 1707 & 0.82 \\
\hline MT16080C & 8 & 16 & 1.6 & 47.0 & 594 & 398 & 1402 & 0.37 \\
\hline МT02090C & 9 & 2 & 1.3 & 22.5 & 902 & 368 & 1448 & 1.00 \\
\hline MT18100C & 10 & 18 & 1.3 & 30.4 & 1023 & 505 & 1725 & 0.42 \\
\hline MT06110C & 11 & 6 & 1.6 & 5.2 & 1262 & 737 & 2285 & 0.50 \\
\hline MT21110C & 11 & 21 & 2.0 & 15.0 & 1025 & 693 & 2153 & 0.27 \\
\hline MT19120C & 12 & 19 & 2.4 & 48.3 & 510 & 499 & 1799 & 0.52 \\
\hline
\end{tabular}

$\mathrm{PAI}=$ plant area index, $\mathrm{SZA}=$ solar zenith angle $(\mathrm{deg}),. \mathrm{PPFD}=$ photosynthetic photon flux density, and correlation is relative to the profile of mean segment PPFD values collected on 2 September.

segments, this corresponds to a mean speed of $0.53 \mathrm{~m} / \mathrm{s}$ and hence a TRAC sampling interval of $1.66 \mathrm{~cm}$. Although we do not have independent data on the characteristic gap (or sunfleck) size in semiarid African woodlands, our sampling interval was less than half of our assumed characteristic leaf size $(4.0 \mathrm{~cm})$. Although the traverse time's standard deviation is nearly $20 \%$ of the mean, the histogram is skewed towards longer traverse times and hence shorter sampling intervals. In such oversampling cases, the derived LAI is not affected. Hence, our TRAC speed seems sufficient.

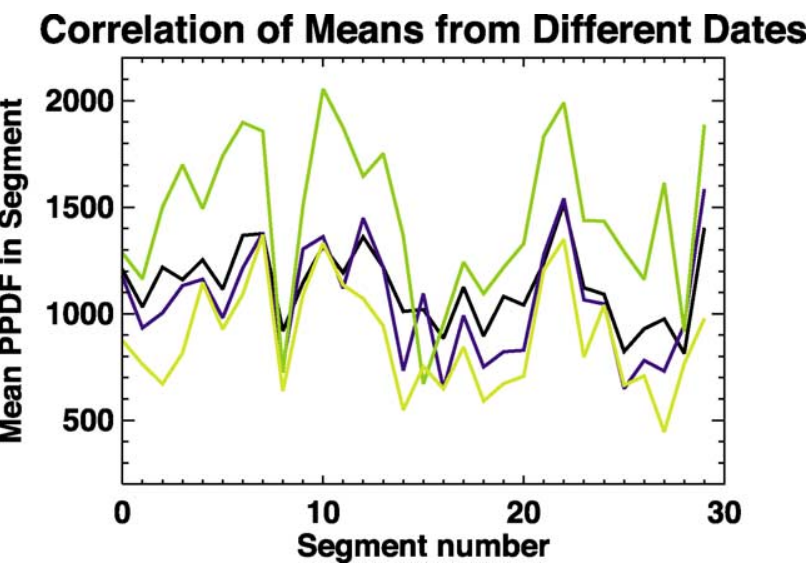

Fig. 5. Mean PPFD values for each segment along Transect B on four dates (June 14, August 5, September 2 and November 6), each collected at a unique solar angle. The relatively high correlation demonstrated that TRAC was consistently responding to varying crown density along the transects. Poorly correlated data sets suggested that TRAC data may be less useful when gathered under high solar zenith angles (e.g., $>69^{\circ}$ ).

\subsection{Within-site spatial evaluation}

Our site-wide PAI sample consisted of 90 values (3 transects $\times 30$ segments/transect, where each value represents the mean PAI over $25 \mathrm{~m}$ ). To assess spatial variability over the area, we determined the PAI density distribution for both a wet (20 April) and a dry (2 September) season case (see summary statistics in Table 2).

Several trends are immediately apparent. First, the wet season PAI is roughly double the dry season value. Not surprisingly, Transect $\mathrm{C}$ has a higher $(<0.4$ units) mean PAI than do Transects $\mathrm{A}$ or $\mathrm{B}$. Because $\mathrm{C}$ is primarily within the Kataba Local Forest, it is subject to less land use pressure (e.g., cropping, harvesting). Besides impacting PAI, varying land use may lead to some differences in age or species. Finally, there is greater variability in the wet season case,

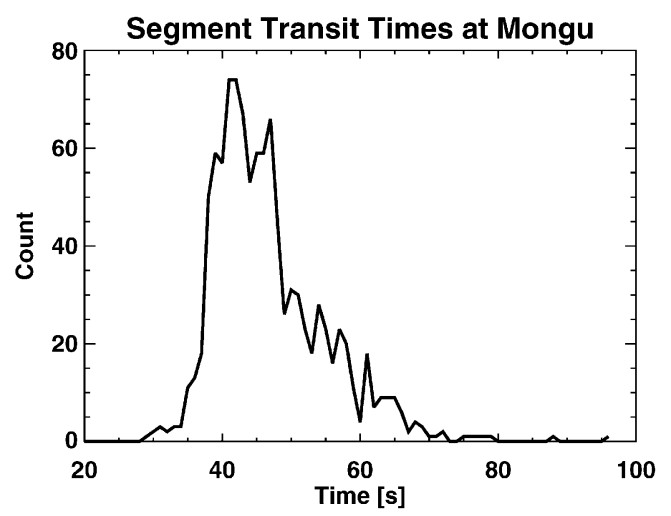

Fig. 6. TRAC segment transit times for 1050 segments gathered through the year at Mongu. The mean transit time corresponds to a horizontal sampling interval of about $1.66 \mathrm{~cm}$. This distance is less than the estimated characteristic sunfleck size, suggesting TRAC is able to completely resolve typical sunflecks. This is required in TRAC software to properly reconstruct the overstory gap size distribution. 
Table 2

Spatial variability of TRAC-derived plant and leaf area indices at Mongu for wet and dry season cases

\begin{tabular}{|c|c|c|c|c|c|c|c|}
\hline \multirow[t]{2}{*}{ Date } & \multirow[t]{2}{*}{ Transect } & \multicolumn{2}{|c|}{ Plant area index } & \multicolumn{4}{|c|}{ Leaf area index } \\
\hline & & Mean & $\mathrm{SD}$ & Mean & Minimum $^{\mathrm{a}}$ & Maximum $^{\mathrm{a}}$ & MODIS $^{\mathrm{b}}$ \\
\hline \multirow[t]{4}{*}{ April 20 (wet season) } & A & 2.3 & 0.9 & $*$ & $*$ & $*$ & $*$ \\
\hline & B & 1.9 & 0.8 & $*$ & $*$ & $*$ & $*$ \\
\hline & $\mathrm{C}$ & 2.6 & 0.9 & $*$ & $*$ & $*$ & $*$ \\
\hline & all & 2.3 & 0.9 & 1.9 & 0.9 & 2.9 & 1.6 \\
\hline \multirow[t]{4}{*}{ September 02 (dry season) } & A & 1.0 & 0.4 & $*$ & $*$ & $*$ & $*$ \\
\hline & B & 1.0 & 0.4 & $*$ & $*$ & $*$ & $*$ \\
\hline & $\mathrm{C}$ & 1.3 & 0.4 & $*$ & $*$ & $*$ & $*$ \\
\hline & all & 1.1 & 0.4 & 0.8 & 0.3 & 1.3 & 0.9 \\
\hline
\end{tabular}

(*) Intentionally left blank.

a The minimum (maximum) values of the range were estimated by subtracting (adding) one standard deviation to the mean, then subtracting the maximum (minimum) estimated stem area index ( 0.4 and 0.3 , respectively).

b The MODIS value is provided for comparison to TRAC values.

both within and between the transects. This was also evident in the correlation testing (see previous section).

The TRAC PAI includes green and senescent leaves, stems and woody material. Thus, to evaluate the MODIS LAI, we estimated the expected range (minimum, maximum) of green LAI from TRAC by subtracting (adding) one standard deviation to the mean PAI, then subtracting the maximum (minimum) estimated stem area index. We did not measure stem area at Mongu, however Asner (1998 and personal communication, 2001) reports that the range $0.3<\mathrm{SAI}<0.4$ is robust over a large sample of North and South American woodlands and savannas. Although we adopt these values, we continue to provide both LAI and the original PAI values through the remainder of this article such that readers can consider or apply other SAI values as desired.

The MODIS LAI is well within our TRAC-derived LAI ranges (Table 2). Relative to the TRAC mean LAI, the

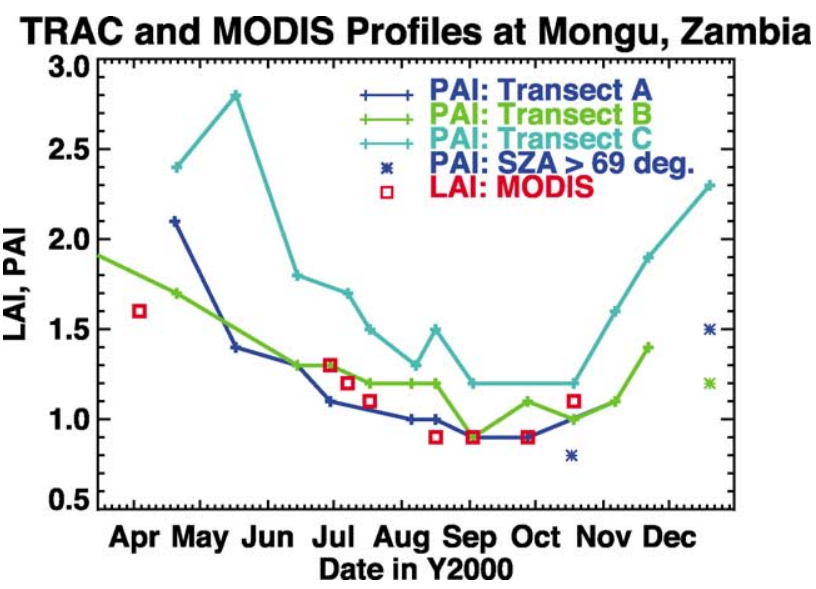

Fig. 7. Mean PAI values for each transect through the year at Mongu, Zambia. Note the PAI of Transect C (that occurring primarily within the Kataba Forest) is higher than for the other transects throughout the year, especially in the wet season. The red squares show the MODIS LAI values for the study site. The asterisks indicate PAI values from data collected when the solar zenith angle was larger than $69^{\circ}$, under which conditions the derived values appear less accurate. The colors of the asterisk symbols correspond to the transect colors shown in the legend.
MODIS value is 0.3 units less in the wet season, but 0.1 units larger in the dry season. Because TRAC represents overstory, LAI and MODIS represents total LAI, the MODIS wet season value appears to underestimate the true LAI in the April (wet season) case.

Next, we compared the TRAC PAI and MODIS LAI estimates for April through December (see Fig. 7). There are several trends to note. First, the temporal PAI profiles of the transects exhibit similar seasonal profiles, with Transect C having consistently higher values. The MODIS LAI follows a similar trajectory as expected. Both depict leaf loss during senescence in May through July, with minimum foliar biomass in September, and green-up beginning in October. MODIS data also suggest that the lowest LAI conditions occurred near early September. This is consistent with miombo species (Storrs, 1995), which begin generating roots and leaves before the onset of the wet season (first rains typically in October; fully established wet season in

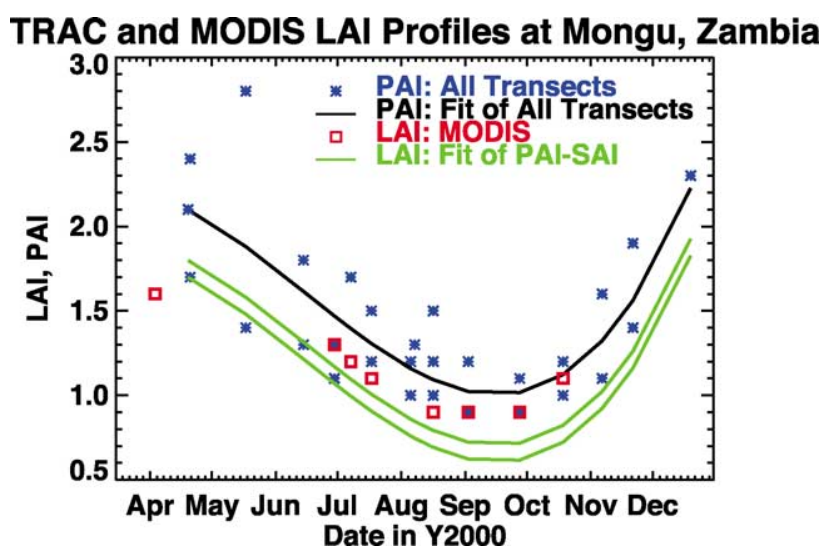

Fig. 8. Comparison of TRAC-derived green LAI range and MODIS green LAI values. The TRAC-derived PAI curve was determined by fitting the PAI data with a third-order polynomial, and the LAI range was determined by subtracting the maximum and minimum SAI values suggested by Asner (1998 and personal communication, 2001) from the PAI curve. Only PAI values from data collected when the solar zenith angle was lower than $69^{\circ}$ were used to fit the curve. 
November). Together, the findings suggest the MODIS LAI product is showing reasonable behavior throughout the miombo phenological cycle.

To estimate quantitative agreement, we fit the mean PAI values for each transect and date with a third-order polynomial (standard error $=0.3$, Chi squared fit $=2.6$ ), then subtracted the typical upper (0.4) and lower (0.3) SAI values suggested by Asner (1998 and personal communication, 2001). The results are shown in Fig. 8. Except for the April date (noted above), the TRAC LAI are lower than the MODIS LAI as would be expected since TRAC only views overstory. Both data sets suggest a gradual decrease in leaf area from April through September, followed by a sharp green-up beginning in October. The mean difference between the TRAC LAI (assuming SAI $=0.35$ ) and the MODIS LAI is 0.2 (standard deviation $=0.2$ ). Predictably, the largest error occurs for April just after MODIS commenced operations (i.e., poorest instrument characterization).

\subsection{Kalahari Transect spatial evaluation}

Although the temporal comparisons at Mongu suggest appropriate MODIS product behavior for different phenological periods, they do not show the product's behavior for different vegetation structural conditions. Indeed, the crown heights and spacing were effectively constant at the Mongu site.

The other sites along the Kalahari exhibited markedly different canopy structural characteristics (see Site Descriptions and Fig. 2 above). Therefore, we compared the mean TRAC values, determined over the three transects at each site, with the MODIS value. Due to inconsistent MODIS operations and cloud frequency in March 2000, the MODIS LAI could not always be generated for these sites on or near the TRAC sampling date. Thus, we generalized two classes of savanna, the first including Pandamatenga and Maun, the second including Okwa and Tshane. We determined a single LAI for each class by finding mean MODIS LAI of cloud-free grid cells within $10 \times 10 \mathrm{~km}$ boxes centered on the study sites between March 22 and April 6. This approach assumes that areas around the study sites are structurally similar. This seems reasonable based on inspection of the LAI histograms for the $10 \times 10$ sample sets. Further, due to expected stability in the vegetation phenology between the TRAC and MODIS sampling dates, we assume any differences in time are minimal compared to inter-site differences. Results are shown in Fig. 9.

Again, the MODIS LAI shows reasonable behavior. The MODIS LAI exceeded the TRAC LAI for Maun, Okwa and Tshane as would be expected, but was less than the TRAC value at Mongu and equal at Pandamatenga. The mean difference between the TRAC LAI (assuming SAI $=0.35$ ) and the MODIS LAI over all sites is 0.2 (standard deviation $=0.3$ ). The greatest difference occurred for Okwa,

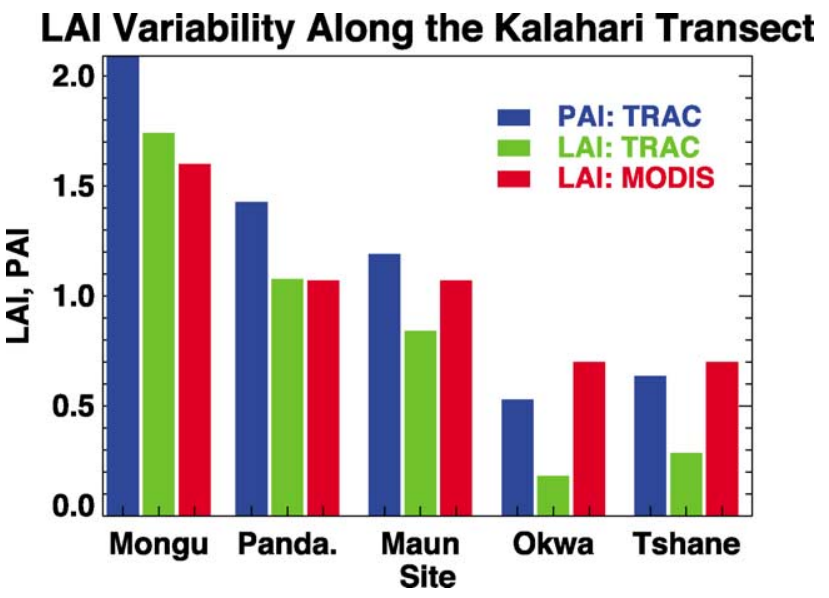

Fig. 9. Mean TRAC PAI, TRAC-derived LAI, and MODIS LAI product values for five structurally different sites along the Kalahari Transect in March 2000. Pandamatenga is abbreviated as Panda. See text for details on the MODIS LAI estimates. Note the Mongu TRAC data were collected on April 19 and 20 since cloudiness prevented sufficient measurements at this site during the Kalahari Campaign.

however, that result is consistent with the height of vegetation there relative to the TRAC operational height.

\section{Discussion}

Given the timing of the Kalahari Campaign and this assessment relative MODIS' initial operations, the results are encouraging. They suggest that the MODIS LAI algorithm is generating sensible values over southern Africa, and is accommodating different phenological states and structural attributes (different degrees of crown shadowing, overstory and understory prevalence, and bare soil exposure). Although there is a current effort to reprocess early MODIS products (using the MODAPS V003 system), initial comparisons suggest the reprocessed LAI values are quantitatively similar to the initial product values for semiarid vegetation. This is particularly true in cases of low atmospheric aerosol loading (AOT $<0.15$ at $550 \mathrm{~nm}$ ), a condition that was common along the Kalahari during the wet season campaign (M. Mukelabai, unpublished data). Thus, we expect our results to change little upon MODIS reprocessing. Other limitations to our results are discussed below.

We have considered MODIS LAI behavior for different canopy phenological states and structures to assess robustness. Nevertheless, the statistical significance of a comparison on any one date or site is limited by the use of a single MODLAND LAI grid cell - specifically, the one overlapping the sampling area. This problem is somewhat mitigated by the aggregation of up to16 samples ( $250 \mathrm{~m}$ resolution) in the $1 \mathrm{~km}$ reflectance product used by the LAI algorithm. Aggregation increases the signal-to-noise ratio, i.e., reduces random errors. There are two practical methods for increasing the MODIS sample size per site and date. First, we could collect ground data over larger areas (e.g., $5 \times 5 \mathrm{~km}$ ). Recall 
that although our method provides 93 LAI estimates per site and date, each is a mean value determined over $25 \mathrm{~m}$ (i.e., from about 1500 TRAC measurements). Thus, an expanded sampling area would require additional resources. Second, we could scale the ground data over larger areas using other data sources. Tian et al. (in press) comprehensively address this issue for the Maun site using data collected alongside our TRAC data, together with Landsat and IKONOS imagery. Other approaches are discussed in Campbell, Burrows, Gower, \& Cohen (1999) and Weiss et al. (2001).

Second, our estimates of the MODIS LAI uncertainty assume that stem area index data from North and South American savanna systems (specifically Texas, New Mexico, Chile and Brazil; Asner, 1998) can be applied to Kalahari systems. Some species sampled in the ancillary data, e.g., Prosopis glandulosa (mesquite), are fine-leaved evergreen shrubs reminiscent of some African acacia species. We hope to measure SAI at some Kalahari sites in future work to evaluate the accuracy of this assumption. As noted above, the provision of PAI values throughout this article allows readers to consider other SAI ranges. As with any method used to estimate LAI from light obscuration methods, we must assume that there is equal probability that a stem is obscuring light or that a leaf is obscuring light. In the wet season, it seems likely that leaves more typically cover woody components. This may explain why the MODIS LAI is outside the range of TRAC PAI in the peak dry season (Fig. 7), but is within the range of measured PAI when foliar biomass is higher.

Third, the understory LAI was not adequately estimated with the TRAC system as it was used in this study. Typically, TRAC was held just below waist level (approximately $0.7 \mathrm{~m}$ ) during sampling. Foliage below that height can be indirectly characterized using data from the downlooking PAR sensor on TRAC, however, the current version of TRAC software does not use that data. For Mongu and most of the other Kalahari sites (predominately excepting Okwa River Crossing), the majority of leaf area was in the overstory, and hence visible to TRAC uplooking sensor. Thus, we speculate that the omission of understory introduced only a small error, particularly at the northern sites (This is confirmed with other data sources in Privette et. al., 2002). At Pandamatanga, there were a few areas of dense grass. However, most of that area had only sparse grass probably due to grazing. At Okwa, most leaf area was in grass and fairly low shrubbery, suggesting our TRACderived LAI is least accurate for this site.

The generality of our MODIS assessment may also be limited by ecosystem. Kalahari soils are sandy and relatively bright (typically a medium gray color), although moisture and litter tends to darken them. Since soils in woodlands and savannas tend to be more exposed than in other ecosystems, the MODIS LAI algorithm may perform differently elsewhere. Still, it was encouraging that algorithm results were accurate in both wet (darker soil) and dry (bright soil) seasons.
Just as the error budget is considered in generating the MODIS LAI product, it must be used to interpret our optical estimates of LAI. However, the dependence on proprietary software or destructive samples makes this task difficult. Each of the other limitations noted above will be addressed in future work.

Obviously, comprehensive evaluation of the MODIS LAI product requires independent data from many worldwide sites and biomes before uncertainty claims can be made about the product. An evaluation at more than 25 sites was recently initiated through an international working group on LAI validation (Privette, Morisette, Baret, Gower, \& Myneni, 2001). Results from this effort, together with community recommendations on "best practice" field and data protocols, will be provided in future publications.

\section{Conclusions}

In this study, we derived leaf area index from optical measurements, and compared these data to the operational MODIS LAI product. These data were collected at four sites along the IGBP Kalahari Transect in Botswana in March 2000 , and monthly at one site in western Zambia from March through December. The MODIS product captured the phenology in a Kalahari Woodland, from peak-biomass in March-April (latter part of wet season), senescence, peak dry season and minimum foliar biomass in early September, and rapid green-up into the next wet season. The LAI varied between 0.8 and about 1.9 through that period. Further, the MODIS LAI product also captured the decreasing LAI from Mongu, Zambia (LAI 1.7) through Tshane, Botswana $(\mathrm{LAI}<0.5)$ in the wet season. We conclude that first-year MODIS LAI $1 \mathrm{~km}$ product performed well for African semiarid woodlands and savannas.

\section{Acknowledgements}

The Kalahari Transect campaign was successfully accomplished only with the help and cooperation of the whole team. We sincerely thank all who participated. We appreciate the help of C. Chirara, B. Mantlana, and K. Tabor in defining transects. We particularly thank L. Otter, B. Scholes, T. Suttles, S. Ringrose, O. Totolo, D. Lesolle, E. Veenendaal, F. Nortje, H. Annegarn and B. Swap for the extensive logistical help, and the Governments of Zambia and Botswana for their gracious hosting of our activities. We also thank the reviewers of the original manuscript for their helpful comments. This study was part of the SAFARI 2000 Initiative. The TRAC data used in this study are available via the Oak Ridge Data Active Archive Center's Mercury system. All MODIS data are available via the EROS Data Center. 


\section{References}

Asner, G. P. (1998). Biophysical and biochemical sources of variability in canopy reflectance. Remote Sensing of Environment, 64, 234-253.

Campbell, J. L., Burrows, S., Gower, S. T., \& Cohen, W. B. (1999). Bigfoot Field Manual, Ver. 2.1. Oak Ridge National Laboratory (p. 216, ORNL/TM).

Chen, J. M. (1996). Optically-based methods for measuring seasonal variation in leaf area index in boreal conifer stands. Agricultural and Forest Meteorology, 80, 135-163.

Chen, J. M., \& Cihlar, J. (1995). Plant canopy gap size analysis theory for improving optical measurements of leaf area index. Applied Optics, 34, $6211-6222$.

Chen, J. M., Leblanc, S. G., \& Kwong, M. (2000). Manual for TRAC. Ottawa: Canada Centre for Remote Sensing.

Chen, J. M., Pavlic, G., Brown, L., Cihlar, J., Leblanc, S. G., White, H. P. Hall, R. J., Peddle, D., King, D. J., Trofymow, J. A., Swift, E., Van der Sanden, F. J., \& Pellikka, P. (2002). Derivation and validation of Canada-wide coarse-resolution leaf area index maps using high-resolution satellite imagery and ground measurements. Remote Sensing of Environment, 80(1), 165-184.

Dowty, P., Frost, P., Lesolle, P., Midgley, G., Mukelabai, M., Otter, L., Privette, J., Ramontsho, J., Ringrose, S., Scholes, B., \& Wang, Y. (2000). Summary of the SAFARI 2000 wet season field campaign along the Kalahari Transect. EOS Earth Observations, 12(3), 29-34.

Justice, C. O., Starr, D., Wickland, D., Privette, J. L., \& Suttles, T. (1998). EOS land validation coordination: an update. EOS Earth Observations, 10(3), 55-60.

Justice, C. O., Vermote, E., Townshend, J. R. G., Defries, R., Roy, D. P., Hall, D. K., Salomonson, V. V., Privette, J. L., et al. (1998). The MODerate Resolution Imaging Spectroradiometer (MODIS): land remote sensing for global change research. IEEE Transactions on Geoscience and Remote Sensing, 36(4), 1228-1249.

Kaufman, Y. J., Herring, D. D., Ranson, K. J., \& Collatz, G. J. (1998). Earth observing system AM1 mission to Earth. IEEE Transactions on Geoscience and Remote Sensing, 36(4), 1045-1055.

Knyazikhin, Y., Martonchik, J. V., Diner, D. J., Myneni, R. B., Verstraete, M., Pinty, B., \& Gobron, N. (1998). Estimation of vegetation leaf area index and fraction of absorbed photosynthetically-active radiation from atmosphere-corrected MISR data. Journal of Geophysical Research, $103,32239-32256$.

Knyazikhin, Y., Martonchik, J. V., Myneni, R. B., Diner, D. J., \& Running, S. W. (1998). Synergistic algorithm for estimating vegetation canopy leaf area index and fraction of absorbed photosynthetically active radiation from MODIS and MISR data. Journal of Geophysical Research, 103, 32257-32274

Leblanc, S. G. (2002). Correction to the plant canopy gap size analysis theory used by the Tracing Radiation and Architecture of Canopies instrument. Applied Optics (in press).

Miller, E. E., \& Norman, J. M. (1971). A sunfleck theory for plant canopies: I. Length of sunlit segments along a transect. Agronomy Journal, 63, $735-738$.

Myneni, R. B., Asrar, G., \& Gerstl, S. A. W. (1990). Radiative transfer in three-dimensional leaf canopies. Transport Theory and Statistical Physics, 19, 205-250.
Myneni, R. B., Hoffman, S., Knyazikhin, Y., Privette, J. L., Glassy, J., Tian, Y., Wang, Y., Song, X., Zhang, Y., Smith, G. R., Lotsch, A., Friedl, M., Morisette, J. T., Votava, P., Nemani, R. R., \& Running, S. W. (2002). Global products of vegetation leaf area and fraction absorbed PAR from year one of MODIS data. Remote Sensing of Environment, 83, 214-231 (this issue).

Nilson, T. (1971). A theoretical analysis of the frequency of gaps in plant stands. Agricultural and Forest Meteorology, 8, 25-38.

Privette, J. L. (2000). Southern Africa Validation of NASA's Earth Observing System (SAVE EOS). Proc. IJPRS Remote Sensing, 2000, Cape Town.

Privette, J. L., Asner, G. P., Conel, J., Huemmrich, K. F., Olson, R., Rango, A., Rahman, A. F., Thome, K., \& Walter-Shea, E. A. (2000). The Prototype Validation Exercise (PROVE) at Jornada: overview and lessons learned. Remote Sensing of Environment, 74(1), 1-12.

Privette, J.L, Morisette, J., Baret, F., Gower, S. T., \& Myneni, R. B. (2001). Summary of the international workshop on LAI product validation. EOS Earth Observations, 13(3), 18-22.

Privette, J.L., Tian, Y., Roberts, G., Scholes, R.J., Wang, Y., Caylor, K.C., Frost, P., \& Mukelabai, M. (2002). Structural characteristics and relationships of kalahari woodlands and savannas. Global Change Biology, (submitted)

Ringrose, S., \& Chanda, R. (Eds.) (2000). Towards sustainable management in the Kalahari Region: some essential background and critical issues (p. 304). Gaborone: Directorate of Research and Development, University of Botswana.

Scholes, R. J., \& Parsons, D. A. B. (Eds.) (1997). The Kalahari Transect: Research on Global Change and Sustainable Development in Southern Africa, IGBP Report 42 (p. 61). Stockholm: IGBP Secretariat.

Steffen, W. (2000). The IGBP terrestrial transects: tools for resource management and global change research at the regional scale. In S. Ringrose, \& R. Chanda (Eds.), Towards Sustainable Management in the Kalahari Region: Some Essential Background and Critical Issues (pp. 1-12). Gaborone: Directorate of Research and Development, University of Botswana.

Storrs, A. E. G. (1995). Know Your Trees: Some Common Trees Found in Zambia. Lusaka, Zambia: Regional Soil Conservation Unit.

Swap, R. J., \& Annegarn, H. (Eds.) (1999). Southern African Regional Science Initiative: SAFARI 2000: Science Plan, Available at http:// safari.gecp.virginia.edu.

Tian, Y., Woodcock, C. E., Wang, Y., Privette, J. L., Shabanov, N. V., Zhou, L., Buermann, W., Dong, J., Veikkanen, B., Hame, T., Ozdogan, M., Knyazikhin, Y., \& Myneni, R. B. (2002). Multiscale Analysis and Validation of the MODIS LAI Product over Maun, Botswana. Remote Sensing of Environment (in press).

Weiss, M., de Beaufort, L., Baret, F., Allard, D., Bruguier, N., \& Marloie, O. (2001). Mapping leaf area index measurements at different scales for the validation of large swath satellite sensors: first results of the VALERI project. Proceedings of the 8th International Symposuim on Physical Measurements and Signatures in Remote Sensing, Aussois, France, 8-12 January (pp. 125-130).

Wolfe, R. E., Roy, D. P., \& Vermote, E. (1998). MODIS land data storage, gridding and compositing methodology: level 2 grid. Remote Sensing of Environment, 36(4), 1324-1338. 